\title{
The Comparison and Simulation for the Response and Following of the Power Plant Coordination Control Scheme
}

\author{
Yun Zhou \\ School of North China Electric Power University, Baoding 071000, China; \\ 15028260178@163.com
}

Keywords: Intelligent coordination control, Power plant, The matlab simulation

\begin{abstract}
This paper mainly analyzes the control strategy of multivariable control system via state feedback decoupling control and coordinated control strategy, these three aspects of the simulation, simulated furnace with machine and machine with furnace control strategy, and comparative analysis. then we make the conclusion: furnace with machine operation mode, if make power strong adaptability, the pressure fluctuation is large, so it is suitable for the predominantly turbine operation mode; Machine with the furnace operation mode, if the pressure fluctuation is small, then the power adaptability is bad, so it is suitable for the predominantly boiler operation mode; Coordinate operation mode are better able to compromise on either side of the furnace control quality, with strong ability to adapt and anti-jamming performance, but the program structure is complex. While the system parameter setting is difficult, only limited on the level of the simulation are not enough.
\end{abstract}

\section{Introduction}

Coordinated control system is the unit load control system, by the turbine and boiler coordinated action, which realizes the unit load control. On the one hand, the control unit give output power to satisfy the requirement of electric load; Each subsystem, on the other hand, coordination of turbine and boiler pressure before control machine, to stable operation of the unit. Coordinated control system according to the feedback loop classification of coordinated control system can be divided into based on turbine following boiler (basic of boiler) coordinated control system and based on boiler following (basic of turbine) turbine coordinate control system.

\section{The Machine with Furnace}

When the external load demand changes, change the boiler load first. When the main steam pressure make the rating of deviation, adjust the steam turbine regulating valve opening, to maintain pressure constant before turbine machine.

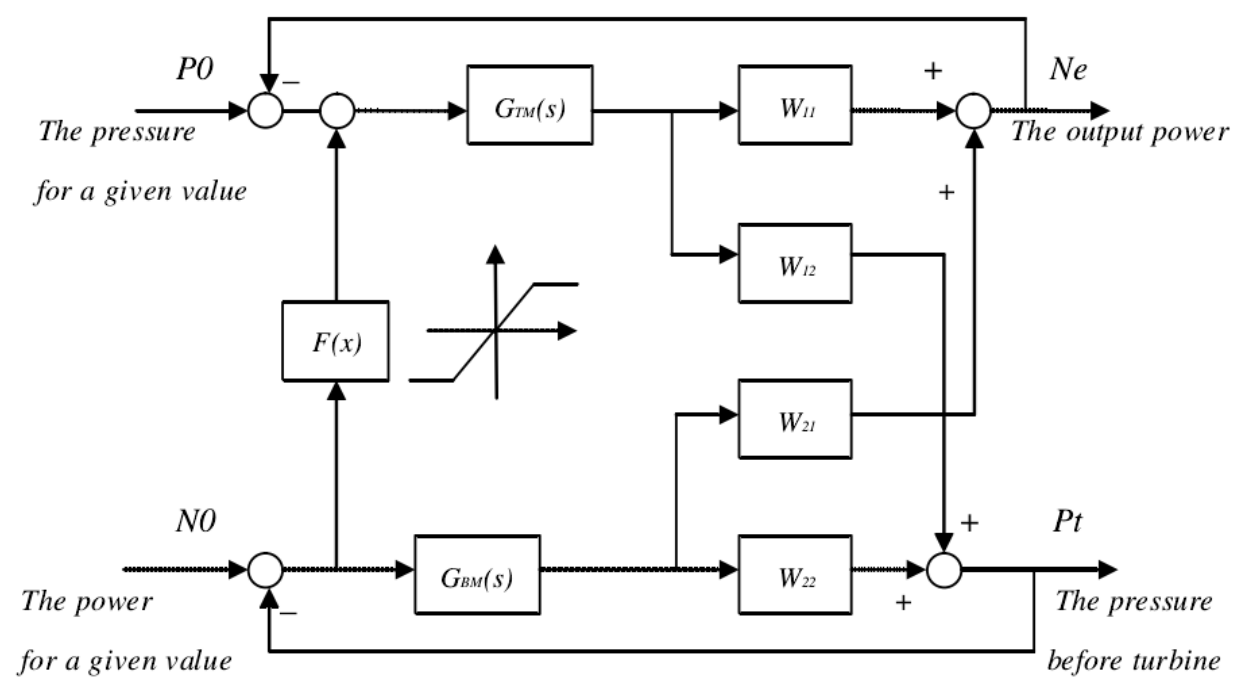

Fig. 1 The model of machine with furnace 
As shown in the above figure, the turbine follow (basic) boiler control system including the main steam pressure control system of steam turbine side and side of the boiler unit power control system.

The boiler regulator $G_{B M}(s)$ Accept the power of a power feedback signal and power given signal, when the unit load changes, of all, we control the amount of fuel through the boiler regulator $G_{B M}(s)$ firstly.

After the standby pressure Pt change, and then according to the machine before the pressure and the deviation of a given value, $G_{T M}(s)$ The change of steam turbine control valve opening through the turbine governor, so as to change the power unit.

\section{The Furnace with Machine}

When external load demand changes, firstly change of steam turbine regulating valve opening, change into steam, the output of generating unit adapted to external load demand, at this time it would cause the machine before pressure rating. Boiler based on the machine before the pressure deviation adjustment combustion rate and the feed water flow, eliminate the main steam pressure deviation, finally reaching a new energy balance.

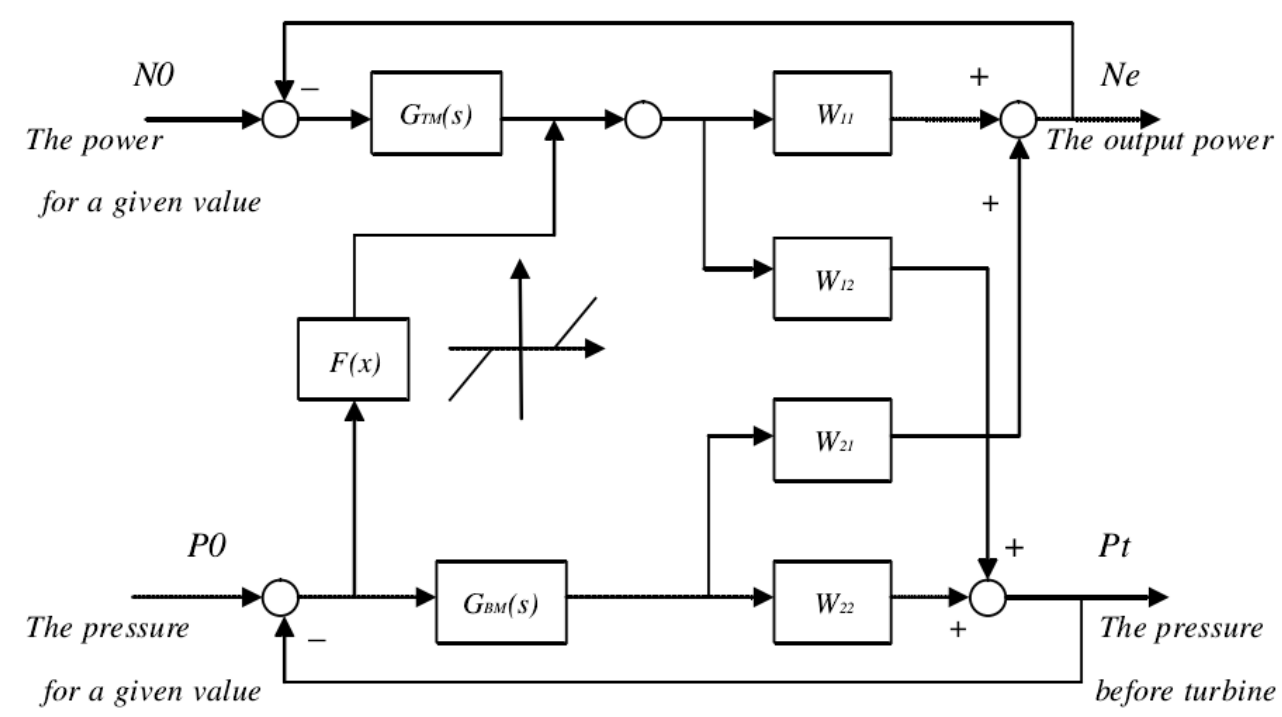

Fig. 2 The model of furnace with machine

Turbine governor $G_{T M}(s)$ can accept power given value and the net power feedback signal, according to the deviation between them, adjust the opening of turbine control valve, which changes into steam generator output power meet the load demand quickly. Boiler regulator $G_{B M}(s)$ would accept machine pressure setting value and machine before the pressure feedback signal, according to the deviation between them, adjust the amount of fuel to ensure the stability of main steam pressure.

\section{The Results of Simulation and Image Analysis}

\section{Step1.Machine with furnace}

Making sure the pressure before turbine is constant, the pressure of a given value $\mathrm{P} 0=0$, N0 for a given power unit step signal, then the system simulates.

The simulation results are as follows: 


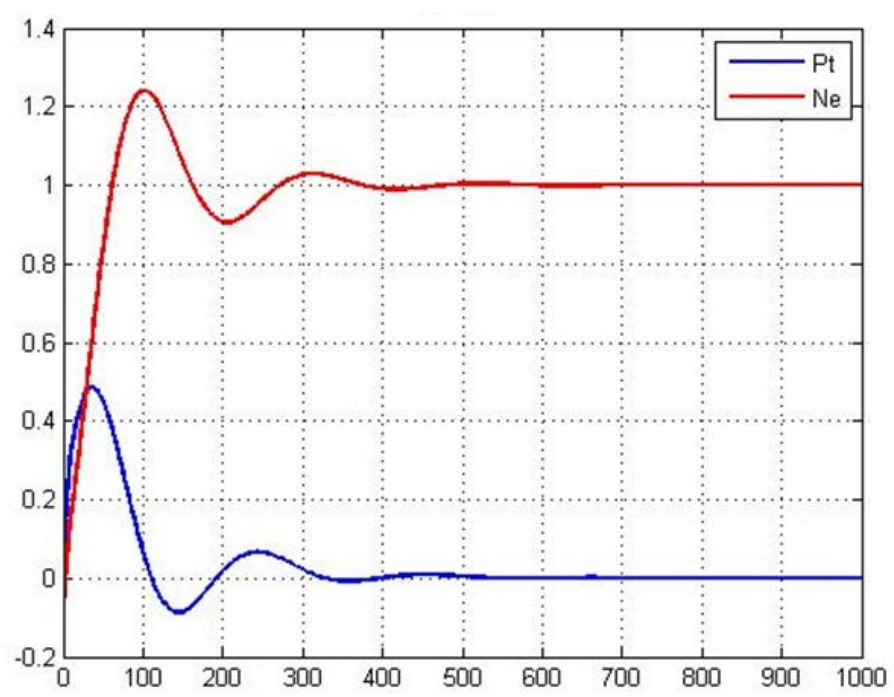

Fig. 3 The system response of machine with furnace

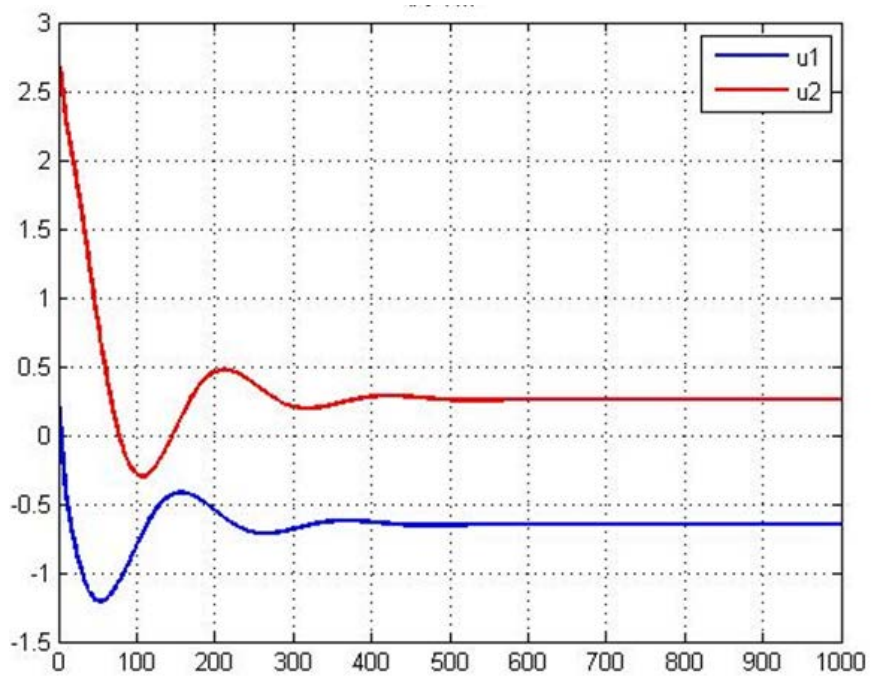

Fig. 4 The controller response of machine with furnace Controller parameters: PI1: $\delta_{1}=0.5, T i_{1}=100$; PI2: $\delta_{2}=0.4, T i_{2}=200$

\section{Step2.Furnace with machine}

Making the machine before pressure is constant, set the pressure of a given value $\mathrm{P} 0=0$, N0 for a given power unit step signal, then put the system simulated.

The simulation results are as follows:

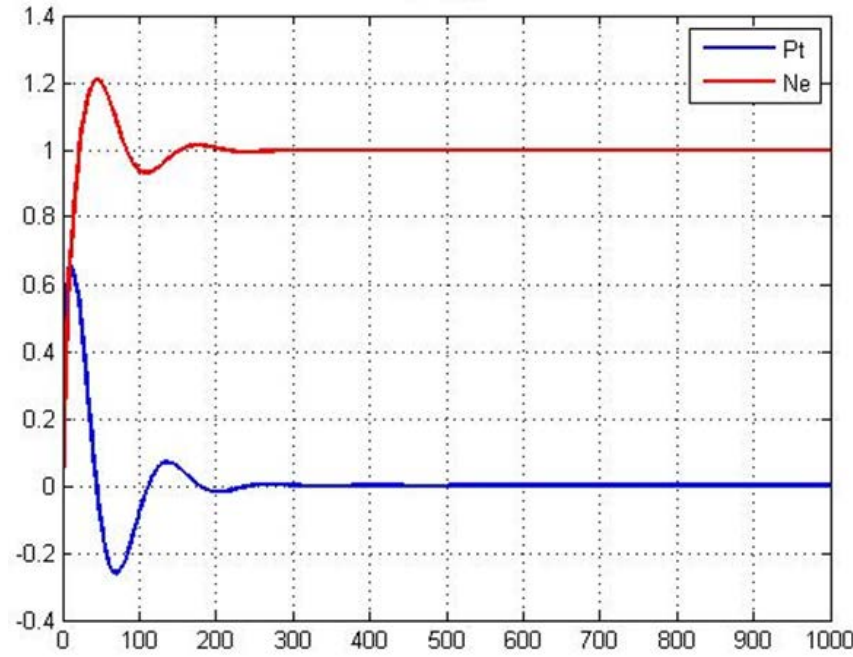

Fig. 5 The system response of furnace with machine 


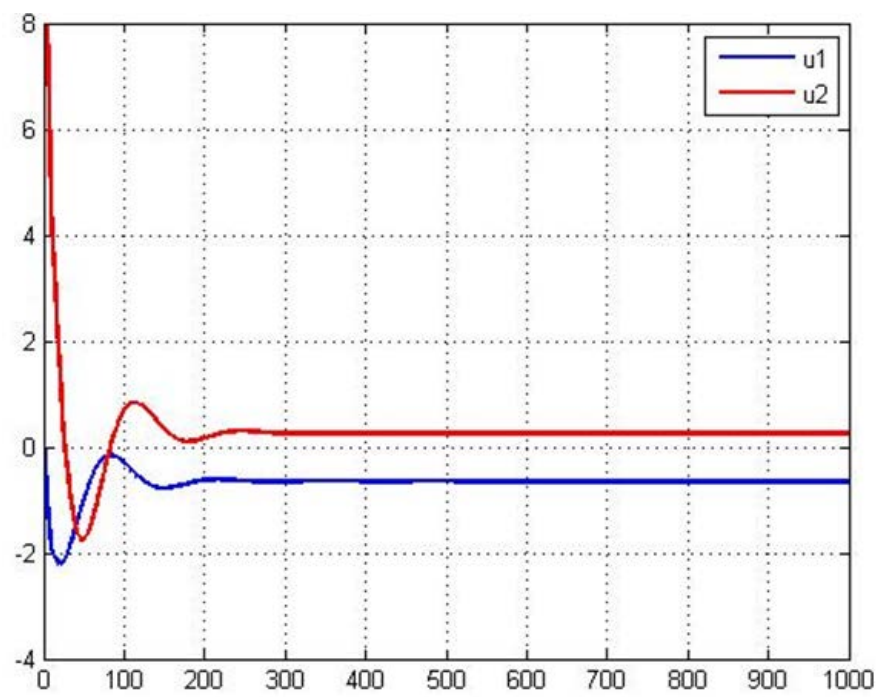

Fig. 6 The controller response of furnace with machine

Controller parameters:PI1: $\delta_{1}=0.4, \mathrm{Ti}_{1}=35$;PI2: $\delta_{2}=0.1, \mathrm{Ti}_{2}=153$

\section{Conclusion}

Can see from figure 3, adopting the strategy of machine with furnace, boiler parts first move and the fuel quantity increase, thus machine pressure Pt before increase with the increase of fuel quantity, steam turbine parts with random pressure before action, along with the change of Pt change steam turbine valve opening, stable machine before turbine .

From figure 5 as you can see, the strategy with the furnace machine, steam turbine first move, the turbine side valve opening increases, thus reduced pressure Pt before machine, boiler parts with random pressure before action, increases with the change of the Pt fuel quantity, making increased stable before steam pressure and make the machine running well.

\section{References}

[1] Yang Zhousheng. Environment and Coal-fired power plants [M]. Anhui Normal University Press, 2011.

[2] Deng Xue, Li Jiaming, Zeng Haojian. Research on Calculation Methods of simulinking Weight Vector and Its Application [J]. Mathematics in practice and theory, 2012, 07:93-100. 